\title{
MicroRNA-208a-3p contributes to connexin40 remolding in human chronic atrial fibrillation
}

\author{
SHANSHAN LI $^{1 *}$, ZHIYUAN JIANG $^{1,2^{*}}$, LINA WEN $^{1}$, GUIRONG FENG $^{1}$ and GUOQIANG ZHONG ${ }^{1}$ \\ ${ }^{1}$ Department of Cardiology; ${ }^{2}$ Hypertension Division, The First Affiliated Hospital, \\ Guangxi Medical University, Nanning, Guangxi 530021, P.R. China
}

Received March 16, 2017; Accepted July 27, 2017

DOI: $10.3892 /$ etm.2017.5225

\begin{abstract}
Previous studies have demonstrated that connexin40 (Cx40) remolding is involved in atrial fibrillation (AF). GJA5 encoding Cx40 is a potential target mRNA of microRNA-208a-3p (miR-208a-3p), as indicated by preliminary bioinformatics analyses. However, the exact effect of miR-208a-3p on Cx40 in human chronic AF has remained elusive. The present study demonstrated the role of miR-208a-3p in human chronic AF and further investigated the effect of miR-208a-3p on Cx40 expression. A total of 19 patients with AF and 18 patients with sinus rhythm (SR) were enrolled. The AC16 cell line was treated with miR-208a-3p inhibitor or mimics. The miR-208a-3p in right atrial appendage (RAA) tissues of patients was measured by in situ hybridization and reverse-transcription quantitative polymerase chain reaction (RT-qPCR). Furthermore, the expression of $\mathrm{Cx} 40$ in the RAA of patients and in AC16 cells treated with miR-208a-3p inhibitor or mimics were detected by RT-qPCR and western blot analysis. A luciferase assay was performed to confirm whether $\mathrm{Cx} 40$ was directly targeted by miR-208a-3p. The miR-208a-3p levels in patients with AF were significantly increased compared with those in patients with SR. Conversely, the Cx40 protein levels were significantly decreased and lateralization of $\mathrm{Cx} 40$ was observed in patients with AF. miR-208a-3p inhibitor led to a significant upregulation of the protein expression of Cx40 in AC16 cells, while miR-208a-3p mimics led to a significant downregulation. However, the luciferase assay demonstrated that GJA5 was not a direct target gene of miR-208a-3p. The findings still suggested that miR-208a-3p may be involved in human chronic
\end{abstract}

Correspondence to: Dr Guoqiang Zhong, Department of Cardiology, The First Affiliated Hospital, Guangxi Medical University, 22 Shuangyong Road, Nanning, Guangxi 530021, P.R. China

E-mail: gq_zhong@126.com

*Contributed equally

Key words: atrial fibrillation, microRNA-208a-3p, connexin40, human, AC16 cell line
AF by mediating atrial $\mathrm{Cx} 40$ remolding, and may represent a potential therapeutic target for AF.

\section{Introduction}

Atrial fibrillation (AF) is the most common type of arrhythmia and is associated with increased cardiovascular morbidity and mortality (1). Current drug treatments of AF have moderate efficacy and numerous limitations, including proarrhythmia and bleeding complications in particular (2). An enhanced understanding of the molecular mechanisms of AF is required to develop novel interventions for AF.

Although the pathogenesis of AF has remained to be fully elucidated, focal ectopic activity and re-entry are thought to be the two major determinants of AF initiation and maintenance independent of the underlying causes (2). The decelerated conduction and shortened refractoriness contribute to the formation of re-entry (3). The gap junction, which connects the cytoplasm of adjacent cells, is a key regulator of conduction in the heart (4). Gap junctions are clustered channels, consisting of two hemichannels, each of which is formed by six connexins (Cxs) (5). Cx40 is one of the principal atrial gap junction proteins (6). Igarashi et al (7) have demonstrated that gene therapy with adenovirus expressing Cx40 or Cx43 preserves atrial conduction and prevents AF in a swine model. This indicated that interventions targeting $\mathrm{Cx} 40$ may be promising for AF therapy. However, the specific regulatory mechanisms of $\mathrm{Cx} 40$, particularly at the post-transcriptional level, remain to be fully elucidated in human AF.

microRNAs (miRs) are a class of small, non-coding RNAs of $\sim 22$ nucleotides in length, which negatively regulate target gene expression at the post-transcriptional level (8). They generally bind to a complementary sequence in the 3'-untranslated regions (3'UTRs) of their target mRNAs, which results in degradation of the mRNA or inhibition of its translation (8). In recent years, a number of studies have demonstrated that dysregulation of certain miRs is associated with AF-maintaining substrates by promoting atrial remolding, including electrical and structural remolding $(9,10)$. Previous studies have indicated that miR-208 may be involved in the pathogenesis of $\mathrm{AF}(11,12)$, but at present, the exact role of miR-208 in human AF is poorly understood. Of note, preliminary bioinformatics analyses revealed that CJA5 encoding Cx40 is a potential target gene of miR-208a-3p. Therefore, the 
present study investigated whether miR-208a-3p was responsible for AF by targeting Cx40 directly.

\section{Materials and methods}

Collection of human atrial samples. A total of 37 patients with valvar heart disease undergoing cardiac surgery at the First Affiliated Hospital, Guangxi Medical University between March 2015 and August 2015 were divided into a chronic AF group [19 cases with long-standing, persistent AF (13); 9 males, 10 females; average age, $51.53 \pm 9.81$ years] and a sinus rhythm (SR) group (8 males, 10 females; average age, $47.78 \pm 10.10$ years; Table I). The diagnosis of AF was reached by evaluating medical records and 12-lead electrocardiogram findings. Those who had hypertension, diabetes mellitus, coronary heart disease, infective endocarditis, active rheumatism, pulmonary disease, hyperthyroidism or autoimmune disease were excluded from this study. The protocol was in accordance with the Helsinki Declaration and was approved by the Human Ethics Committee of the First Affiliated Hospital of Guangxi Medical University (Guangxi, China). All patients enrolled in this study provided written informed consent.

Right atrial appendage (RAA) tissues weighing $150 \mathrm{mg}$ were removed at the beginning of the surgical interventions under extracorporeal circulation. A portion of the tissues was fixed in $4 \%$ paraformaldehyde for $24 \mathrm{~h}$ at $4{ }^{\circ} \mathrm{C}$ and then embedded in paraffin. The remainder of the tissues was snap-frozen in liquid nitrogen for protein and RNA isolation.

In situ hybridization (ISH) analysis. The expression of miR-208a-3p in RAA was characterized by ISH with a double (3' and 5') digoxigenin (DIG)-labelled locked nucleic acid modified probe (5'-ACAAGCTTTTTGCTCGTCTTAT-3'; Exiqon, Vedbaek, Denmark). Paraffin-embedded tissues sections were hybridized in $100 \mathrm{ml}$ hybridization buffer (Exiqon) with 50 pM denatured DIG-labelled probe overnight at $42^{\circ} \mathrm{C}$. The sections were then washed with $1 \mathrm{X}$ saline-sodium phosphate EDTA buffer [8.765 $\mathrm{g} \mathrm{NaCl}, 1.38 \mathrm{~g} \mathrm{NaH}_{2} \mathrm{PO}_{4}$ and $0.37 \mathrm{~g} \mathrm{EDTA}-\mathrm{Na}_{2} \cdot 2 \mathrm{H}_{2} \mathrm{O}$ dissolved in $500 \mathrm{ml}$ diethyl pyrocarbonate (DEPC) $\mathrm{H}_{2} \mathrm{O}, \mathrm{pH}$ 7.4] and incubated with an anti-DIG-alkaline phosphatase antibody (cat. no. 11093274910; Roche, Mannheim, Germany) diluted 1:2,000 in 1X blocking buffer (2\% sheep serum; cat no. 013-000-121; Jackson ImmunoResearch Laboratories, Inc., West Grove, PA, USA) and $0.1 \%$ Triton $\mathrm{X}-100$ dissolved with $100 \mathrm{mM}$ Tris- $\mathrm{HCl}$ and $150 \mathrm{mM} \mathrm{NaCl}, \mathrm{pH} 7.5$ at room temperature for $2 \mathrm{~h}$. The sections were then stained with $45 \mu \mathrm{g}$ nitroblue tetrazolium in $10 \mathrm{ml}$ of a solution of $50 \mathrm{ml}$ Tris (pH 7.5), $10 \mathrm{ml} 5 \mathrm{M} \mathrm{NaCl}$ and $25 \mathrm{ml} 1 \mathrm{M} \mathrm{MgCl}_{2}$ in $500 \mathrm{ml} \mathrm{DEPC} \cdot \mathrm{H}_{2} \mathrm{O}$ (pH 9.0) for $12 \mathrm{~h}$ and imaged under a light microscope.

Reverse-transcription quantitative polymerase chain reaction (RT-qPCR) analysis. Total RNA was extracted from tissues and cells with TRIzol reagent (Invitrogen; Thermo Fisher Scientific, Inc., Waltham, MA, USA). The miRs were extracted from tissues with RNAiso for Small RNA reagent (Takara Bio Inc., Otsu, Japan).

Total RNAs were reverse-transcribed into complementary (c)DNA using a PrimerScript ${ }^{\mathrm{TM}}$ RT reagent kit with a gDNA eraser (cat. no. RR047A, Takara Bio Inc.) according to the manufacturer's protocols. The PCR mixture contained $2 \mu \mathrm{l}$ cDNA as a template, $10 \mu 1 \mathrm{SYBR}^{\circledR}$ Premix Ex Taq (Takara Bio Inc.), $0.4 \mu \mathrm{l}$ ROX Reference Dye (50X), $0.8 \mu \mathrm{l}$ each of forward and reverse primer $(10 \mu \mathrm{M}$; Table II) and $6 \mu \mathrm{l}$ RNase-free deionized (d) $\mathrm{H}_{2} \mathrm{O}$ filled up to a final volume of $20 \mu$ l. The PCR procedure was as follows: one cycle at $95^{\circ} \mathrm{C}$ for $30 \mathrm{sec}$, followed by 40 cycles of $95^{\circ} \mathrm{C}$ for $5 \mathrm{sec}$ and $60^{\circ} \mathrm{C}$ for $31 \mathrm{sec}$. Melting curve analysis was performed at $65-95^{\circ} \mathrm{C}$. GAPDH was used as the internal standard for normalizing gene expression.

The miRs were polyadenylated and subsequently converted into cDNAs using a Mir-X ${ }^{\mathrm{TM}}$ miRNA First-Strand Synthesis kit (Clontech Laboratories, Inc., Mountain View, CA, USA) according to the manufacturer's protocols. The PCR mixture contained $2 \mu \mathrm{lcDNA}$ as the template, $12.5 \mu \mathrm{l}$ SYBR Advantage Premix (2X; Clontech Laboratories, Inc.), $0.5 \mu 1$ ROX Reference Dye (50X), $0.5 \mu 1$ of each of the mRQ 3' Primer (Clontech Laboratories, Inc.) and miR-specific $5^{\prime}$ primer $(10 \mu \mathrm{M}$; Table II) and $9 \mu \mathrm{l}$ RNase-free $\mathrm{dH}_{2} \mathrm{O}$ to a final volume of $25 \mu \mathrm{l}$. The PCR procedure was identical to that mentioned above. U6 small nuclear RNA (Clontech Laboratories, Inc.) was used as the internal standard for normalizing gene expression. All the data obtained were calculated by the $2^{-\Delta \Delta \mathrm{Cq}}$ method (14).

Prediction of miR-208a-3p target mRNAs. The target mRNAs of miR-208a-3p were predicted using the following three databases: TargetScan (http://www.targetscan.org/), miRanda (http://www.microrna.org/microrna/home.do) and RNAhybird (http://bibiserv.techfak.uni-bielefeld.de/rnahybrid) (15-17). Those consistently identified by the three databases were regarded as potential target mRNAs. It was demonstrated that GJA5 may be a potential target mRNA of miR-208a-3p, as the latter exhibited binding to the 3'-untranslated region (UTR) of Cx40 mRNA (Fig. 1).

Immunohistochemistry (IHC). Paraffin-embedded tissues sections $4 \mu \mathrm{m}$ thick were routinely dewaxed in xylene and rehydrated in an ethanol gradient series (100, 90, 80, 75 and $50 \%$ ), followed by triple washing with PBS. Antigen retrieval was performed at high pressure in sodium citrate buffer (pH 6.0) at $125^{\circ} \mathrm{C}$ for $10 \mathrm{~min}$. The sections were blocked for $1 \mathrm{~h}$ at room temperature with endogenous peroxidase blockers (cat no. PV-9000, Golden Bridge International, Inc., Bothell, WA, USA) and stained with anti-Cx40 antibody (cat. no. ab38580 Abcam, Cambridge, UK) diluted at 1:200 overnight at $4^{\circ} \mathrm{C}$. Sections were then stained with polyperoxidase-conjugated anti-mouse immunoglobulin (Ig) $\mathrm{G}$ (diluted according to the manufacturer's protocol; cat. no. PV-9000, Golden Bridge International, Inc.) for $1 \mathrm{~h}$ at room temperature. The signals were then visualized using a diaminobenzidine kit (cat. no. ZLI-9017, Zhongshan Goldenbridge Bio, Beijing, China) and observed under a microscope.

Western blot analysis. Total protein was extracted from tissues and cells using radioimmunoprecipitation assay buffer (Beyotime Institute of Biotechnology, Shanghai, China) with phenylmethylsulfonyl fluoride (Sigma-Aldrich; Merck KGaA, Darmstadt, Germany). The protein concentration was determined with a bicinchoninic acid protein assay kit (Beyotime Institute of Biotechnology, Inc.). The proteins were boiled with 4X SDS loading buffer (Takara Bio Inc.) and separated 
Table I. Characteristics of patients with SR or AF.

\begin{tabular}{|c|c|c|c|}
\hline Characteristics & SR group $(n=18)$ & AF group $(n=19)$ & P-values \\
\hline Age (years) & $47.78 \pm 10.10$ & $51.53 \pm 6.14$ & 0.179 \\
\hline Sex (male) & $8(44.4)$ & $9(47.4)$ & 0.746 \\
\hline \multicolumn{4}{|l|}{ Cardiac disease type } \\
\hline MS & 0 & $2(10.5)$ & - \\
\hline MI & $3(16.7)$ & $1(5.3)$ & 0.604 \\
\hline MS+MI & $1(5.6)$ & $2(10.5)$ & 0.604 \\
\hline AI & $1(5.6)$ & 0 & - \\
\hline CVL & $13(72.2)$ & $14(73.7)$ & 0.714 \\
\hline Left atrial thrombus & $1(5.6)$ & $6(31.6)^{\mathrm{a}}$ & 0.090 \\
\hline $\mathrm{LAD}(\mathrm{mm})$ & $46.06 \pm 7.57$ & $65.16 \pm 9.81^{\mathrm{a}}$ & $\mathrm{P}<0.001$ \\
\hline LVEF (mm) & $62.75 \pm 9.69$ & $63.32 \pm 7.54$ & 0.844 \\
\hline \multicolumn{4}{|l|}{ NYHA class } \\
\hline II & $12(66.7)$ & $7(36.8)$ & 0.194 \\
\hline III & $5(27.8)$ & $9(47.4)$ & 0.184 \\
\hline IV & $1(5.5)$ & $3(15.8)$ & 0.340 \\
\hline
\end{tabular}

${ }^{\mathrm{a}} \mathrm{P}<0.01$ vs. SR group, Values are expressed as $\mathrm{n}(\%)$ or the mean \pm standard deviation. MS, mitral stenosis; MI, mitral inadequacy; AI, aortic inadequacy; CVL, combined valvular lesion; LAD, left atrial diameter; LVEF, left ventricular ejection fraction; NYHA, New York Heart Association; SR, sinus rhythm; AF, atrial fibrillation.

Table II. Primers of target genes.

\begin{tabular}{lll}
\hline Target gene & Primer & Base sequence \\
\hline Cx40 & Sense & 5'-TCCTCGGAGTAGTGGTGAGATG-3' \\
& Antisense & 5'-AAAGCTGAGGCTGCTGGTAAAG-3' \\
GAPDH & Sense & 5'-GCACCGTCAAGGCTGAGAAC-3' \\
& Antisense & 5'-TGGTGAAGACGCCAGTGGA-3' \\
miR-208a-3p & Sense & 5'-ATAAGACGAGCAAAAAGCTTGT-3' \\
U6 & Sense & 5'-GGAACGATACAGAGAAGATTAGC-3' \\
& Antisense & 5'-TGGAACGCTTCACGAATTTGCG-3' \\
\hline
\end{tabular}

Cx40, connexin 40; miR, microRNA.

\section{Position 1911 to 1917 of GJA5 3' UTR 5'-UAAAAUGUGUAAUUUGUCUUAAU-3' |||||| \\ hsa-miR-208a-3p

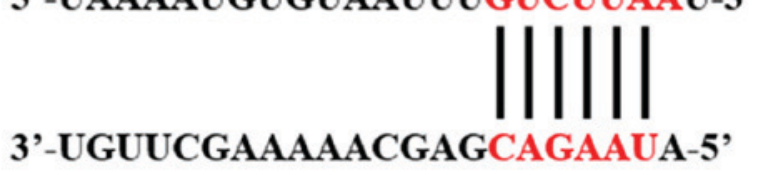

Figure 1. Predicted site of miR-208a-3p binding to GJA5 mRNA. miR, microRNA; UTR, untranslated region; hsa, Homo sapiens.

by $10 \%$ SDS-PAGE, followed by transfer onto a $0.22-\mu \mathrm{m}$ polyvinylidene difluoride membrane (EMD Millipore, Billerica, MA, USA) using the Mini Trans-Blot electrophoretic transfer cell system (Bio-Rad Laboratories, Inc., Hercules, CA, USA). Membranes were blocked for $0.5 \mathrm{~h}$ at room temperature with $5 \%$ non-fat milk in a buffer of $20 \mathrm{mM}$ Tris- $\mathrm{HCl}, 0.5 \mathrm{M} \mathrm{NaCl}$ and $0.1 \%$ Tween 20 , and incubated with anti-Cx40 antibody (Abcam) diluted at 1:1,000 overnight at $4^{\circ} \mathrm{C}$. Subsequently, the membranes were incubated with IRDye $800 \mathrm{CW}$ goat anti-mouse IgG (cat. no. 926-68071, LI-COR Biotechnology, Inc., Lincoln, NE, USA) diluted at 1:10,000 for $1 \mathrm{~h}$ at room temperature. The signals were detected and quantified with the Odyssey system (LI-COR Biotechnology, Inc.). Protein band intensities were expressed relative to $\beta$-tubulin, which was incubated with $\beta$-tubulin antibody overnight at $4^{\circ} \mathrm{C}(1: 10,000$; cat no. AF0524, Affinity Biologicals, Inc. Ancaster, ON, Canada). 
A

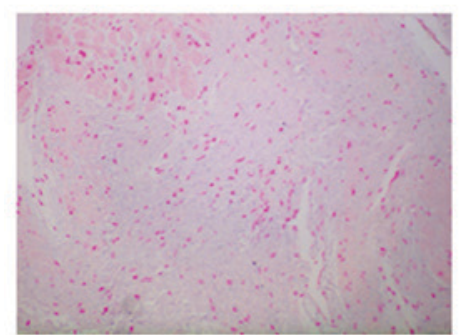

SR

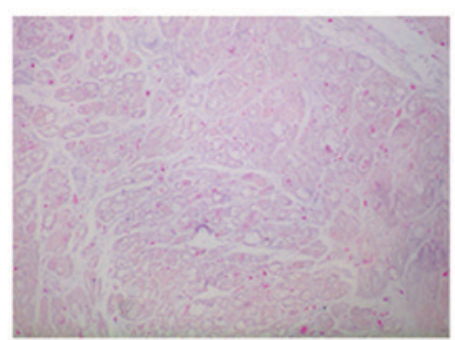

AF

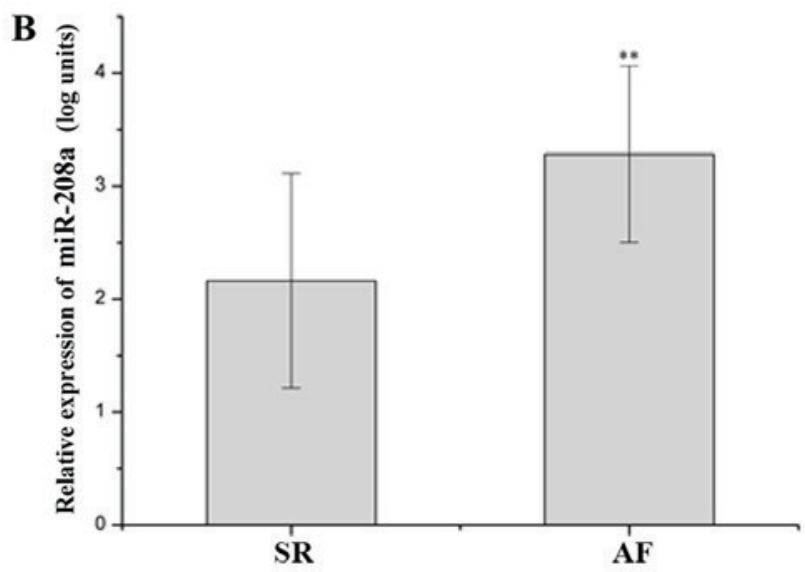

Figure 2. Expression of miR-208a-3p in human RAA. (A) Representative histological sections with in situ hybridization staining for miR-208a-3p (violet staining; magnification, x100). (B) Relative expression of miR-208a-3p in human RAA determined by reverse-transcription quantitative polymerase chain reaction ( $\mathrm{n}=18$ in SR group, $\mathrm{n}=19$ in AF group). Logarithmic transformation was performed for the data that was not normally distributed. ${ }^{* *} \mathrm{P}<0.01 \mathrm{vs}$. SR group. miR, microRNA; RAA, right atrial appendage; SR, sinus rhythm; AF, atrial fibrillation.

Transfection with miR-208a-3p inhibitor or mimics. To determine the effect of miR-208a-3p on Cx40 expression in cardiomyocytes, the AC16 cell line (18) (American Type Culture Collection, Manassas, VA, USA) was treated with miR-208a-3p inhibitor or mimics, respectively. The sequences were as follows: miR-208a-3p inhibitor, 5'-ACAAGCUUU UUGCUCGUCUUAU-3'; miR inhibitor negative control (NC), 5'-CAGUACUUUUGUGUAGUACAA-3'; miR-208a-3p mimics sense, 5'-AUAAGACGAGCAAAAAGCUUGU-3' and antisense, 5'-AAGCUUUUUGCUCGUCUUAUUU-3'; miR mimics NC sense, 5'-UUCUCCGAACGUGUCACGUTT-3' and antisense, 5'-ACGUGACACGUUCGGAGAATT-3'. The AC16 cells were cultured in 24-well plates for $24 \mathrm{~h}$ and subsequently transfected with $80 \mathrm{nM}$ miR-208a-3p inhibitor, miR inhibitor NC, miR-208a-3p mimics or miR mimics NC (Genepharma, Shanghai, China) using X-tremeGENE small interfering (si)RNA Transfection reagent (Roche Diagnostics, Basel, Switzerland) diluted in serum-free Opti-MEM ${ }^{\circledR} \mathrm{I}$ medium (Thermo Fisher Scientific, Inc.) according to the manufacturer's protocols. AC16 cells without siRNA and miR mimics and inhibitors served as a blank control, it should be noted that the experiments using miR inhibitors and mimics were not performed simultaneously, which accounts for the different results for their respective blank controls. The cells were collected for determination of Cx40 expression at $48 \mathrm{~h}$ after transfection.

Luciferase assay. To assess whether GJA5 was directly targeted by miR-208a-3p, a luciferase assay was performed. The 293T cell line (Cell Bank of the Chinese Academy of Sciences, Shanghai, China) was cultured in 24-well plates for $24 \mathrm{~h}$ prior to transfection. Subsequently, the cells were co-transfected with $0.8 \mu \mathrm{g}$ wild-type or mutant-type GJA5-3'UTR of GJA5 mRNA luciferase reporter plasmid (Genepharma) and $40 \mathrm{nM}$ miR-208a-3p mimics or miR mimics NC (Genepharma) using Lipofectamine 2000 (Invitrogen; Thermo Fisher Scientific, Inc.) diluted in Opti-MEM ${ }^{\circledR}$ I reduced serum medium (Invitrogen; Thermo Fisher Scientific, Inc.) according to the manufacturer's protocols.
Firefly and Renilla luciferase activities were measured at $48 \mathrm{~h}$ after transfection using the Dual Luciferase Assay System (Promega Corp., Madison, WI, USA), according to the manufacturer's protocols. Firefly luciferase activity was normalized to that of Renilla.

Statistical analysis. All quantitative data are expressed as the mean \pm standard deviation. Statistical significance between 2 groups was assessed by Student's-test and among multiple groups using one-way analysis of variance followed by the least-significant differences post hoc test. $\mathrm{P}<0.05$ was considered to indicate a statistically significant difference. All statistical analyses were performed using SPSS 16.0 (SPSS Inc., Chicago, IL, USA).

\section{Results}

miR-208a-3p is upregulated in RAA of patients with AF. A low expression of miR-208a-3p, which was distributed in the cardiomyocytes and cardiac interstitial spaces, was observed in the SR group, and miR-208a-3p expression was elevated in the AF group as indicated by ISH (Fig. 2A). The miR-208a-3p levels in the AF group were significantly upregulated compared with those in the SR group $(\mathrm{P}<0.01$; Fig. $2 \mathrm{~B})$.

Lateralization and decreased expression of CX40 in RAA of patients with AF. Although no significant difference in $\mathrm{Cx} 40$ mRNA levels was identified between the AF and SR groups ( $\mathrm{P}>0.05$; Fig. 3A), the $\mathrm{Cx} 40$ protein levels in the AF group were decreased by $23.81 \%$ compared with those in the SR group $(\mathrm{P}<0.05$; Fig. 3B).

The expression of $\mathrm{Cx} 40$ in RAA was characterized by IHC. Cx40 was predominantly present at end-to-end connections between cardiomyocytes in the SR group. The presence of $\mathrm{Cx} 40$ at side-to-side connections between cardiomyocytes was markedly increased in the AF group, and reduced expression of Cx40 was observed as well (Fig. 3C).

miR-208a-3p negatively regulates CX40 expression in AC16 cells, but does not directly target GJA5. As human AC16 
A

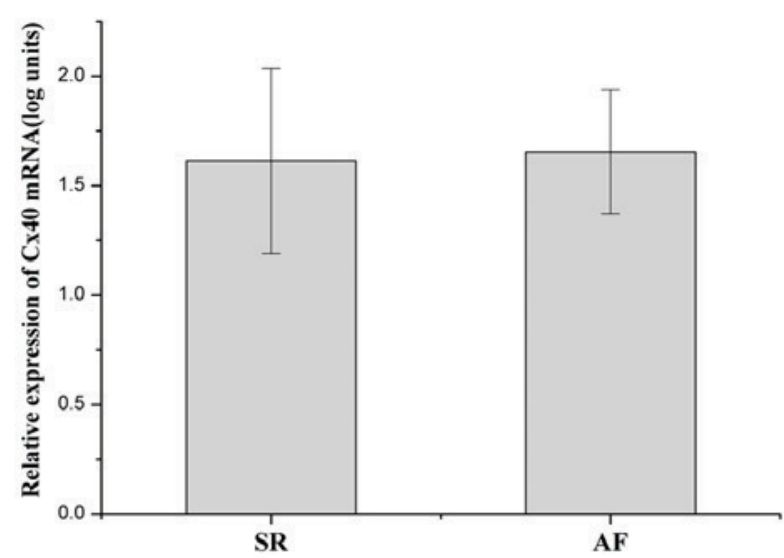

C

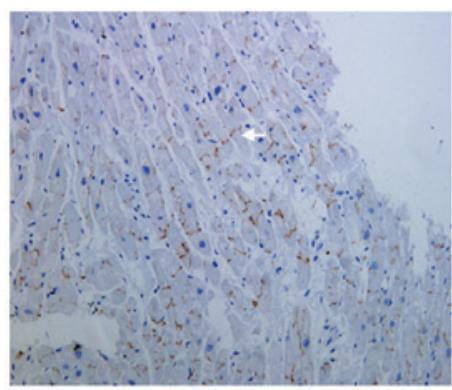

SR

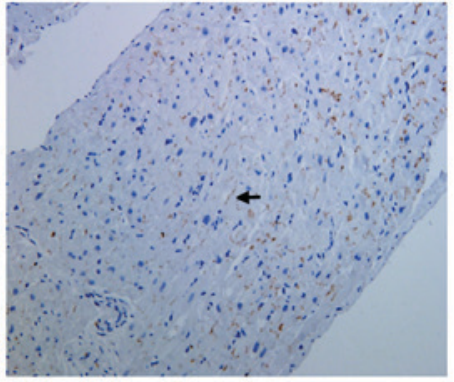

AF
$\mathrm{B}$
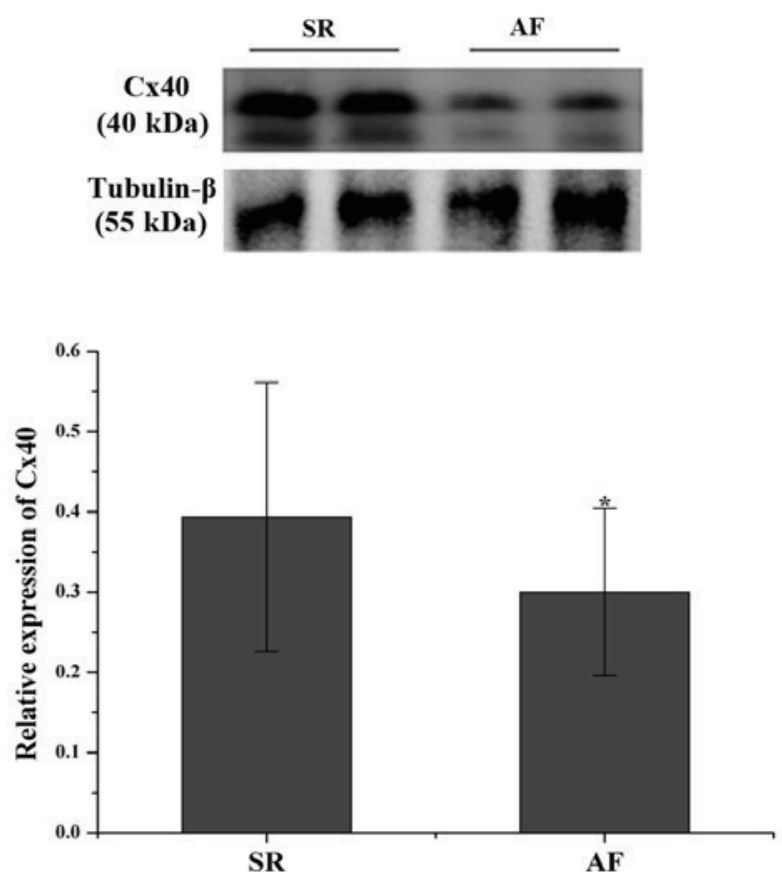

Figure 3. Expression of Cx40 in human RAA. (A) Relative expression of Cx40 mRNA in human RAA determined by reverse-transcription quantitative polymerase chain reaction. Logarithmic transformation was performed for the data that was not normally distributed. (B) Relative expression of Cx40 in human RAA by western blot analysis ( $\mathrm{n}=18$ in SR group, $\mathrm{n}=19$ in AF group). ${ }^{*} \mathrm{P}<0.05$ vs. SR group. (C) Representative histological sections with immunohistochemical staining for $\mathrm{Cx} 40$ (brown; the white arrow represent $\mathrm{Cx} 40$ at the end-to-end connection between the cardiomyocytes; the black arrow represent Cx40 at the side-to-side connection between the cardiomyocytes. Magnification, x200). Cx40, connexin 40; RAA, right atrial appendage; SR, sinus rhythm; AF, atrial fibrillation.

cell line exhibits numerous biochemical and morphological characteristics of cardiac muscle cells (18), it was used in the present study to assess whether Cx40 was regulated by miR-208a-3p in human cardiomyocytes. The expression of $\mathrm{Cx} 40$ was determined in AC16 cells treated with miR-208a-3p inhibitor or mimics. The Cx40 mRNA levels were not significantly different among the miR-208a-3p inhibitor group, the miR inhibitor NC group and the blank control group ( $\mathrm{P}>0.05$; Fig. $4 \mathrm{~A}$ ). However, the $\mathrm{Cx} 40$ protein levels in the miR-208a-3p inhibitor group were upregulated 3.41 -fold compared with those in the miR inhibitor NC group $(\mathrm{P}<0.01$; Fig. $4 \mathrm{~B})$, but there was no significant difference between the miR inhibitor $\mathrm{NC}$ and the blank control group ( $\mathrm{P}>0.05$; Fig. 4B). The Cx40 mRNA levels were not significantly different among the miR-208a-3p mimics group, the miR mimics NC group and the blank control group ( $\mathrm{P}>0.05$; Fig. $4 \mathrm{C})$. However, the $\mathrm{Cx} 40$ protein levels in the miR-208a-3p mimics group was downregulated 3.11-fold compared with that in the miR mimics $\mathrm{NC}$ group $(\mathrm{P}<0.01$; Fig. 4D), while there was no significant difference between the miR mimics $\mathrm{NC}$ and the blank control group $(\mathrm{P}>0.05$; Fig. 4D). These results demonstrated that miR-208a-3p is an upstream negative regulator of $\mathrm{Cx} 40$.

To confirm whether GJA5 was directly targeted by miR-208a-3p, a luciferase assay was performed. However, overexpression of miR-208a-3p did not significantly inhibit the luciferase activity of the reporter plasmid carrying the wild-type 3'-UTR sequence of GJA5 (P>0.05; Fig. 5).

The aforementioned results indicate that although miR-208a-3p did not target GJA5 directly, it was responsible for $\mathrm{Cx} 40$ remolding. The signaling pathways via which miR-208a-3p regulates $\mathrm{Cx} 40$ expression and remolding require further investigation.

\section{Discussion}

Numerous lines of evidence have indicated that variants in GJA5 and its promoter sequence are associated with a predisposition to AF (19-21). Reduced expression and lateralization of Cx40 were identified in atriums of patients with AF and animal models of AF, followed by decreased speed and increased heterogeneity of conduction (22-24). In addition, decelerated atrial conduction and increased vulnerability to atrial arrhythmias were observed in a Cx40-deficient mouse model (25). The present study identified a downregulation of $\mathrm{Cx} 40$ protein levels and lateralization of $\mathrm{Cx} 40$ in RAA tissues of patients with $\mathrm{AF}$ compared with that in patients with SR. These results indicated that $\mathrm{Cx} 40$ remolding is an important contributor to $\mathrm{AF}$.

miR-208 is crucial for the development of cardiomyocytes and the cardiac conduction system (26). Previous studies 
A

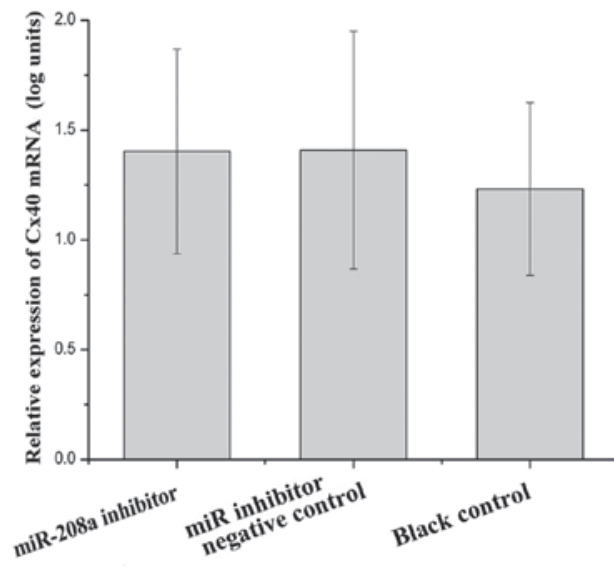

C

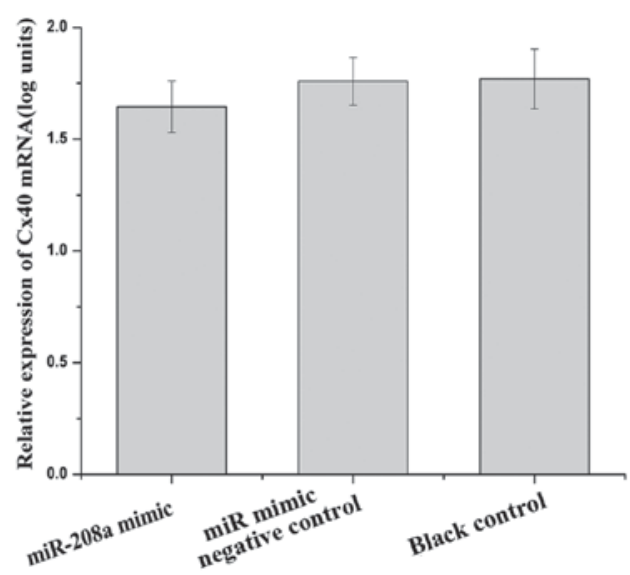

B
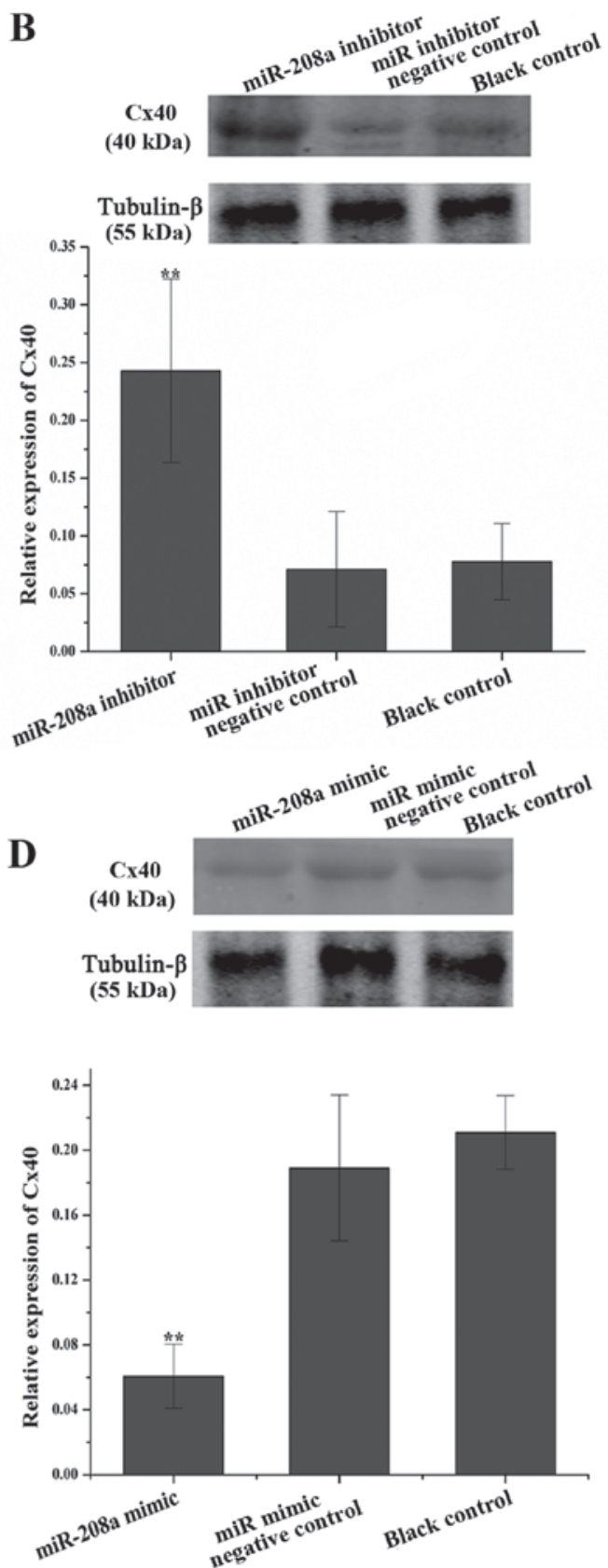

Figure 4. miR-208a-3p negatively regulates Cx40 expression in AC 16 cells. (A) miR-208a-3p inhibitor was not significantly affected by Cx40 mRNA in AC16 cells as determined by RT-qPCR. (B) miR-208a-3p inhibitor significantly elevated Cx40 protein levels in AC16 cells as indicated by western blot analysis. (C) miR-208a-3p mimics did not significantly affect Cx40 mRNA levels in AC16 cells as determined by RT-qPCR. (D) miR-208a-3p mimics significantly decreased $\mathrm{Cx} 40$ protein levels in AC16 cells as indicated by western blot analysis. ${ }^{* *} \mathrm{P}<0.01 \mathrm{vs.} \mathrm{miR}$ mimics/inhibitor negative control group or blank control group. miR, microRNA; Cx40, connexin 40; RAA, right atrial appendage; SR, sinus rhythm; AF, atrial fibrillation; RT-qPCR, reverse-transcription quantitative polymerase chain reaction.

A

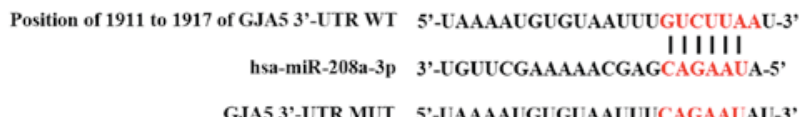

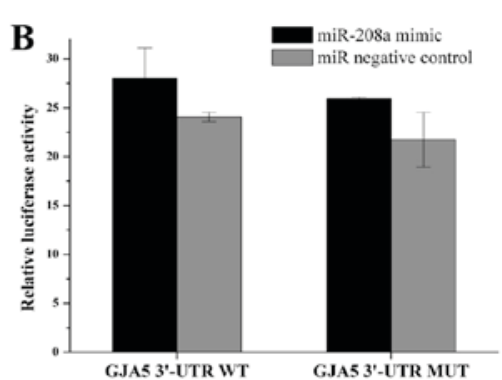

Figure 5. GJA5 is not a direct target gene of miR-208a-3p. (A) Predicted site of miR-208a-3p binding to GJA5 with the wild-type 3'-UTR and design of the MUT sequence. (B) Luciferase assay; overexpression of miR-208a-3p did not significantly inhibit the luciferase activity of the reporter plasmid carrying the wild-type 3'-UTR sequence of GJA5 in 293T cells. miR, microRNA; UTR, untranslated region; WT, wild-type; MUT, mutant-type; hsa, Homo sapiens. 
revealed that miR-208 was involved in various cardiac pathological conditions, including cardiac fibrosis, cardiac hypertrophy, dilated cardiomyopathy and heart failure (27-29). Recently, miR-208 was identified to be closely associated with AF in animal models and patients. First- or second-degree atrioventricular block (AVB) was identified in miR-208a-3p transgenic mice and the majority of miR-208 knockout mice displayed first-degree AVB and AF (30). Nishi et al (11) reported that $\mathrm{miR}-208 \mathrm{~b}$ in the right atrium of patients with AF was elevated compared with that in patients with SR. Radtke et al (12) identified an increase in miR-208a-3p expression in the left atriums from paroxysmal in persistent AF. The present study detected an elevated expression of miR-208a-3p in RAA tissues of patients with AF. It is suggested that the upregulation of miR-208a-3p may promote AF by decelerating atrial conduction (30).

In the present study, a negative association between miR-208a-3p and Cx40 protein levels was identified. Of note, the 3'-UTR of Cx40 mRNA contained a predicted miR-208a-3p target site. In addition, the Cx40 mRNA levels were not significantly different between the SR and the AF groups. Therefore, it was speculated that miR-208a-3p repressed GJA5 expression at the post-transcriptional level by binding to the 3'-UTR of Cx40 mRNA directly. To experimentally verify this, AC16 cells were treated with miR-208a-3p inhibitor or mimics. The results indicated that the Cx40 transcript levels in AC16 cells treated with miR-208a-3p inhibitor or mimics were similar. However, the $\mathrm{Cx} 40$ protein levels were significantly upregulated by miR-208a-3p inhibitor and conversely, treatment with miR-208a-3p mimics significantly downregulated the $\mathrm{Cx} 40$ protein expression. These results further suggested that miR-208a-3p may be involved in AF by targeting Cx40 mRNA directly. Subsequently, a luciferase assay was performed to assess whether GJA5 was directly suppressed by miR-208a-3p. However, co-transfection of miR-208a-3p with the GJA5-3'UTR luciferase reporter vector did not suppress luciferase activity. This result indicated that the negative regulatory effect of miR-208a-3p on Cx40 was not achieved by targeting GJA5 directly. Taken together, these findings demonstrated that miR-208a-3p is responsible for AF by indirectly promoting $\mathrm{Cx} 40$ remolding, and it is an important upstream negative regulatory factor of $\mathrm{Cx} 40$ in human chronic AF.

To the best of our knowledge, the present study was the first to report that miR-208a-3p contributes to $\mathrm{Cx} 40$ remolding in human chronic AF. However, the present study had certain limitations. First, the expression changes of miR-208a-3p and Cx40 were only detected in valvar heart disease patients with long-standing, persistent AF. Patients with other types of cardiovascular disease and those with AF of a different duration require to be examined in the future. Furthermore, the present findings only proved that miR-208a-3p is an upstream negative regulatory factor of $\mathrm{Cx} 40$ in human chronic AF. The specific molecular mechanisms underlying miR-208a-3p-mediated Cx40 remolding require further elucidation. Callis et al (30) reported decreased Cx40 expression in miR-208a-3p knockout mice. They suggested that downregulated Cx40 expression partially resulted from reduced heat shock protein (HSP) 70-Hsp90 organizing protein (Hop) expression. However, as Hop was not directly regulated by miR-208a-3p, they speculated that the reduced Hop expression might stem from increased expression of GATA4, which is targeted by miR-208a-3p directly, but the potential mechanisms of Hop downregulation induced by GATA4 remained elusive. GATA4 is a cardiac transcription factor, which transactivates the Cx40 promoter (31). Therefore, it may be speculated that $\mathrm{Cx} 40$ remolding mediated by miR-208a-3p may be partially associated with downregulation of GATA4 in human AF. However, the mRNA levels of Cx40 were not affected in patients with AF and in AC16 cells treated with miR-208a-3p inhibitor or mimics. This indicated that the mechanisms underlying miR-208a-3p-mediated Cx40 remolding are involved in a complex regulatory network at the transcriptional and post-transcriptional level. Finally, the present study clarified the negative regulatory effect of miR-208a-3p on $\mathrm{Cx} 40$ in vitro. This effect requires to be further verified in vivo.

miR-208a-3p is an important upstream negative regulatory factor of $\mathrm{Cx} 40$ and the upregulation of $\mathrm{miR}-208 \mathrm{a}-3 \mathrm{p}$ was indicated to be responsible for $\mathrm{Cx} 40$ remolding in human chronic AF. This may represent a potential therapeutic target for AF. However, the specific mechanisms underlying miR-208a-3p-mediated Cx40 remolding require further elucidation.

\section{Acknowledgements}

The authors are grateful to Professor Shasha Liu (English Language Department, Guangxi Medical University, Nanning, China) for helping to revise and edit the manuscript. The present study was supported by the National Natural Science Foundation of China (grant no. 81460057).

\section{References}

1. Rahman F, Kwan GF and Benjamin EJ: Global epidemiology of atrial fibrillation. Nat Rev Cardiol 11: 639-654, 2014.

2. Nattel S and Dobrev D: Electrophysiological and molecular mechanisms of paroxysmal atrial fibrillation. Nat Rev Cardiol 13: 575-590, 2016.

3. Wakili R, Voigt N, Kääb S, Dobrev D and Nattel S: Recent advances in the molecular pathophysiology of atrial fibrillation. J Clin Invest 121: 2955-2968, 2011.

4. Bikou O, Thomas D, Trappe K, Lugenbiel P, Kelemen K, Koch M, Soucek R, Voss F, Becker R, Katus HA and Bauer A: Connexin 43 gene therapy prevents persistent atrial fibrillation in a porcine model. Cardiovasc Res 92: 218-225, 2011.

5. Segretain D and Falk MM: Regulation of connexin biosynthesis, assembly, gap junction formation, and removal. Biochim Biophys Acta 1662: 3-21, 2004

6. Davis LM, Kanter HL, Beyer EC and Saffitz JE: Distinct gap junction protein phenotypes in cardiac tissues with disparate conduction properties. J Am Coll Cardiol 24: 1124-1132, 1994.

7. Igarashi T, Finet JE, Takeuchi A, Fujino Y, Strom M, Greener ID, Rosenbaum DS and Donahue JK: Connexin gene transfer preserves conduction velocity and prevents atrial fibrillation. Circulation 125: 216-225, 2012.

8. van Rooij E and Olson EN: MicroRNA therapeutics for cardiovascular disease: Opportunities and obstacles. Nat Rev Drug Discov 11: 860-872, 2012.

9. Luo X, Yang B and Nattel S: MicroRNAs and atrial fibrillation: Mechanisms and translational potential. Nat Rev Cardiol 12: 80-90, 2015.

10. Nattel S and Harada M: Atrial remodeling and atrial fibrillation: Recent advances and translational perspectives. J Am Coll Cardiol 63: 2335-2345, 2014.

11. Nishi H, Sakaguchi T, Miyagawa S, Yoshikawa Y, Fukushima S, Saito S, Ueno T, Kuratani T and Sawa Y: Impact of microRNA expression in human atrial tissue in patients with atrial fibrillation undergoing cardiac surgery. PLoS One 8: e73397, 2013. 
12. Radtke A, Hanke T, Yan J, Godau B, Cordes J, Nigam V, Sievers HH and Mohamed SA: MicroRNA 208 in atrial fibrillation. J Clin Exp Cardiol 5: 325, 2014.

13. January CT, Wann LS, Alpert JS, Calkins H, Cigarroa JE, Cleveland JC Jr, Conti JB, Ellinor PT, Ezekowitz MD, Field ME, et al: 2014 AHA/ACC/HRS guideline for the management of patients with atrial fibrillation: A report of the American College of Cardiology/American Heart Association Task Force on Practice Guidelines and the Heart Rhythm Society. J Am Coll Cardiol 64: e1-e76, 2014.

14. Livak KJ and Schmittgen TD: Analysis of relative gene expression data using real-time quantitative PCR and the 2(-Delta Delta C(T)) method. Methods 25: 402-408, 2001.

15. Agarwal V, Bell GW, Nam JW and Bartel DP: Predicting effective microRNA target sites in mammalian mRNAs. Elife 4, 2015.

16. Betel D, Koppal A, Agius P, Sander C and Leslie C: Comprehensive modeling of microRNA targets predicts functional non-conserved and non-canonical sites. Genome Biol 11: R90, 2010.

17. Rehmsmeier M, Steffen P, Hochsmann M and Giegerich R: Fast and effective prediction of microRNA/target duplexes. RNA 10: $1507-1517,2004$

18. Davidson MM, Nesti C, Palenzuela L, Walker WF, Hernandez E, Protas L, Hirano M and Isaac ND: Novel cell lines derived from adult human ventricular cardiomyocytes. J Mol Cell Cardiol 39: 133-147, 2005.

19. Firouzi M, Ramanna H, Kok B, Jongsma HJ, Koeleman BP, Doevendans PA, Groenewegen WA and Hauer RN: Association of human connexin40 gene polymorphisms with atrial vulnerability as a risk factor for idiopathic atrial fibrillation. Circ Res 95: e29-e33, 2004.

20. Gollob MH, Jones DL, Krahn AD, Danis L, Gong XQ, Shao Q, Liu X, Veinot JP, Tang AS, Stewart AF, et al: Somatic mutations in the connexin 40 gene (GJA5) in atrial fibrillation. N Engl J Med 354: 2677-2688, 2006.

21. Juang JM, Chern YR, Tsai CT, Chiang FT, Lin JL, Hwang JJ, Hsu KL, Tseng CD, Tseng YZ and Lai LP: The association of human connexin 40 genetic polymorphisms with atrial fibrillation. Int J Cardiol 116: 107-112, 2007.
22. Kostin S, Klein G, Szalay Z, Hein S, Bauer EP and Schaper J: Structural correlate of atrial fibrillation in human patients. Cardiovasc Res 54: 361-379, 2002.

23. Rucker-Martin C, Milliez P, Tan S, Decrouy X, Recouvreur M, Vranckx R, Delcayre C, Renaud JF, Dunia I, Segretain D and Hatem SN: Chronic hemodynamic overload of the atria is an important factor for gap junction remodeling in human and rat hearts. Cardiovasc Res 72: 69-79, 2006.

24. Xiao P, Gao C, Fan J, Du H, Long Y and Yin Y: Blockade of angiotensin II improves hyperthyroid induced abnormal atrial electrophysiological properties. Regul Pept 169: 31-38, 2011.

25. Hagendorff A, Schumacher B, Kirchhoff S, Lüderitz B and Willecke K: Conduction disturbances and increased atrial vulnerability in Connexin40-deficient mice analyzed by transesophageal stimulation. Circulation 99: 1508-1515, 1999.

26. Oliveira-Carvalho V, Carvalho VO and Bocchi EA: The emerging role of miR-208a in the heart. DNA Cell Biol 32: 8-12, 2013.

27. van Rooij E, Sutherland LB, Qi X, Richardson JA, Hill J and Olson EN: Control of stress-dependent cardiac growth and gene expression by a microRNA. Science 316: 575-579, 2007.

28. Satoh M, Minami Y, Takahashi Y, Tabuchi T and Nakamura M: Expression of microRNA-208 is associated with adverse clinical outcomes in human dilated cardiomyopathy. J Card Fail 16: 404-410, 2010.

29. Paulin R, Sutendra G, Gurtu V, Dromparis P, Haromy A, Provencher S, Bonnet S and Michelakis ED: A miR-208-Mef2 axis drives the decompensation of right ventricular function in pulmonary hypertension. Circ Res 116: 56-69, 2015

30. Callis TE,Pandya K, Seok HY, Tang RH, Tatsuguchi M, Huang ZP, Chen JF, Deng Z, Gunn B, Shumate J, et al: MicroRNA-208a is a regulator of cardiac hypertrophy and conduction in mice. J Clin Invest 119: 2772-2786, 2009.

31. Linhares VL, Almeida NA, Menezes DC, Elliott DA, Lai D, Beyer EC, Campos de Carvalho AC and Costa MW: Transcriptional regulation of the murine Connexin40 promoter by cardiac factors Nkx2-5, GATA4 and Tbx5. Cardiovasc Res 64: 402-411, 2004. 